\title{
Educational landscapes during and after COVID-
} 19.

\author{
SIEGEL, A.A., ZARB, M., ALSHAIGY, B., BLANCHARD, J., CRICK, T., \\ GLASSEY, R., HOTT, J.R., LATULIPE, C., RIEDESEL, C., SENAPATHI, M., \\ SIMON. and WILLIAMS, D.
}

Permission to make digital or hard copies of all or part of this work for personal or classroom use is granted without fee provided that copies are not made or distributed for profit or commercial advantage and that copies bear this notice and the full citation on the first page. Copyrights for components of this work owned by others than ACM must be honored. Abstracting with credit is permitted. To copy otherwise, or republish, to post on servers or to redistribute to lists, requires prior specific permission and/or a fee. Request permissions frompermissions@acm.org. 


\section{Educational Landscapes During and After COVID-19}

\author{
Angela A. Siegel ${ }^{*}$ \\ Dalhousie University \\ Halifax, NS, Canada \\ siegel@dal.ca \\ Jeremiah Blanchard \\ University of Florida \\ Gainesville, FL, USA \\ jjb@eng.ufl.edu \\ John R. Hott \\ University of Virginia \\ Charlottesville, VA, USA \\ jrhott@virginia.edu \\ Mali Senapathi \\ Auckland University of Technology \\ Auckland, New Zealand \\ mali.senapathi@aut.ac.nz
}

\author{
Mark Zarb* \\ Robert Gordon University \\ Aberdeen, Scotland, UK \\ m.zarb@rgu.ac.uk \\ Tom Crick \\ Swansea University \\ Swansea, Wales, UK \\ thomas.crick@swansea.ac.uk \\ Celine Latulipe \\ University of Manitoba \\ Winnipeg, MB, Canada \\ celine.latulipe@umanitoba.ca \\ Simon \\ University of Newcastle \\ Callaghan, NSW, Australia \\ simon@newcastle.edu.au
}

\author{
Bedour Alshaigy \\ University of Aberdeen \\ Aberdeen, Scotland, UK \\ bedour.alshaigy@abdn.ac.uk \\ Richard Glassey \\ KTH Royal Institute of Technology \\ Stockholm, Sweden \\ glassey@kth.se \\ Charles Riedesel \\ University of Nebraska-Lincoln \\ Lincoln, NE, USA \\ chuckr@unl.edu \\ David Williams \\ Dublin Business School \\ Dublin, Ireland \\ david.williams@dbs.ie
}

\begin{abstract}
The coronavirus (COVID-19) pandemic has forced an unprecedented global shift within higher education in the ways that we communicate with and educate students. This necessary paradigm shift has compelled educators to take a critical look at their teaching styles and use of technology. Computing education traditionally focuses on experiential, in-person activities. The pandemic has mandated that educators reconsider their use of student time and has catalysed overnight innovations in the educational setting.

Even in the unlikely event that we return entirely to pre-COVID19 norms, many new practices have emerged that offer valuable lessons to be carried forward into our post-COVID-19 teaching. This working group will explore what the post-COVID-19 academic landscape might look like, and how we can use lessons learned during this educational shift to improve our subsequent practice. The exploration will strive to identify practices within computing that appear to have been improved through exposure to online tools and technologies, and that should therefore continue to be used in the online space. In the broadest sense, our motivation is to explore what the post-COVID-19 educational landscape will look like for computing education.
\end{abstract}

\section{CCS CONCEPTS}

- Social and professional topics $\rightarrow$ Computing education.

*Working group leader

Permission to make digital or hard copies of part or all of this work for personal or classroom use is granted without fee provided that copies are not made or distributed for profit or commercial advantage and that copies bear this notice and the full citation on the first page. Copyrights for third-party components of this work must be honored For all other uses, contact the owner/author(s).

ITiCSE 2021, June 26-fuly 1, 2021, Virtual Event, Germany

(C) 2021 Copyright held by the owner/author(s).

\section{KEYWORDS}

COVID-19; coronavirus; computing education; online education

ACM Reference Format:

Angela A. Siegel, Mark Zarb, Bedour Alshaigy, Jeremiah Blanchard, Tom Crick, Richard Glassey, John R. Hott, Celine Latulipe, Charles Riedesel, Mali Senapathi, Simon, and David Williams. 2021. Educational Landscapes During and After COVID-19. In 26th ACM Conference on Innovation and Technology in Computer Science Education V. 2 (ITiCSE 2021), June 26-fuly 1, 2021, Virtual Event, Germany. ACM, New York, NY, USA

\section{BACKGROUND}

At the time of writing, mid-2021, we are still in the middle of the COVID-19 global pandemic. While some provisions have been made to facilitate a safe return of students to campus, most teaching is still conducted online, as has been the case for the totality of the current academic year for many institutions. This educational shift has acutely impacted subjects which, traditionally, benefit from inperson activities such as guided labs, experiential learning activities and tutorials. These traditionally in-person activities have been augmented through the use of various technologies and innovative pedagogies to transition to an online environment over the course of the academic year.

Prior to the pandemic, much work has taken place to explore concerns experienced by students transitioning into higher education $[7,8,11,13]$. Students transitioning into higher education during the COVID-19 pandemic encountered an entirely new learning, teaching and assessment reality, and especially through their experiences of "emergency remote teaching" in 2020 [1, 10]. In parallel, the rise of online and hybrid coursework and programs has brought with it investigations of online content delivery. As a community, while we have undertaken pedagogical work to teach students in 
the online environment $[3,5]$, the current, pandemic-affected students are not traditional online learning students - rather, they are face-to-face students who have been forced to rapidly adapt to diverse online learning provision $[10,12]$. It is thus important to capture and analyse both faculty and student experiences and innovations, so as to reflect on lessons learned from these to better inform emerging policies and practice as we move towards a post-COVID-19 educational landscape.

While COVID-19 precipitated many challenges, it also catalysed new and creative modes of engagement in higher education $[1,2,4,9,10]$. Barriers to innovation were lifted to allow for a rapid transition to online teaching and learning. As such, evaluation of and exposure to new tools and learning techniques took place at a faster rate than ever before [6]. It is important that we capture the lessons learned from both students and faculty while the experiences remain fresh.

The objectives of the working group are as follows:

(1) To conduct a multinational study of both faculty and students to better understand the impact of COVID-19 on computing education: educational practices explored will include tools and techniques, for student engagement and teaching practices, that have been employed during the pandemic;

(2) To explore the results of the study to elicit best practices resulting from the impact of COVID-19;

(3) To disseminate the results to the international computing education community.

\section{METHOD}

We will conduct a multinational survey to understand how the teaching of undergraduate-level computing was altered by remote learning during the pandemic. The survey will be circulated at each of the twelve author institutions and also to other computing educators. We will collect contact information from participants willing to participate in follow-up interviews. We anticipate conducting up to 20 follow-up interviews with instructors from a cross-section of institution types, geographic regions, and course levels.

\section{KEY THEMES}

While the exact questions to be asked in surveys and follow-up interviews are still under development, we anticipate asking questions in the following areas:

Value changes: How have your instructional values changed as a result of pandemic teaching, if at all?

Positive new practices: Which practices employed during pandemic teaching have offered unexpected value to students, faculty, learning and/or engagement?

Problem areas: What issues in remote teaching could not be overcome, and led to worse learning outcomes?

Inclusion benefits: Which groups of students thrived in remote learning, and how can they be supported in the future?

Inclusion issues: Which groups of students were harmed in the move to remote teaching? What is being done to reduce and/or redress those harms?

Instructor well-being: What aspects of remote teaching impacted instructor well-being, either positively or negatively?
Student isolation: What techniques/technologies did you use to try to fight isolation and help students feel connected?

Technology use: What technologies in computing education were most valuable during the pandemic?

Common practices: How did common computing education practices, such as pair programming, think-pair-share, code reviews and design crits, change during remote teaching?

Missing tools or practices: Were there any tools or practices that were notable in their absence? What would you like to have had access to, but could not because it wasn't available?

Academic integrity: How did your approach to ensuring academic integrity of assessments change during remote teaching? Did the frequency of academic dishonesty change?

\section{REFERENCES}

[1] Tom Crick, Cathryn Knight, Richard Watermeyer, and Janet Goodall. 2020. The Impact of COVID-19 and "Emergency Remote Teaching" on the UK Computer Science Education Community. In United Kingdom and Ireland Computing Education Research Conference. (Glasgow, United Kingdom) (UKICER '20). ACM, New York, NY, USA, 31-37. https://doi.org/10.1145/3416465.3416472

[2] Tom Crick, Cathryn Knight, Richard Watermeyer, and Janet Goodall. 2021. An Overview of the Impact of COVID-19 and "Emergency Remote Teaching" on International CS Education Practitioners. In Proceedings of the 52nd ACM Technical Symposium on Computer Science Education (Virtual Event, USA) (SIGCSE '21). ACM, New York, NY, USA, 1288. https://doi.org/10.1145/3408877.3439680

[3] Marcia D Dixson. 2010. Creating Effective Student Engagement in Online Courses: What Do Students Find Engaging?. Journal of the Scholarship of Teaching and Learning 10, 2 (2010), 1-13.

[4] Celine Latulipe. 2021. A CS1 Team-Based Learning Space in Gather.Town. In Proceedings of the 52nd ACM Technical Symposium on Computer Science Education (Virtual Event, USA) (SIGCSE '21). ACM, New York, NY, USA, 1245. https: //doi.org/10.1145/3408877.3439587

[5] Mary Lou Maher, Celine Latulipe, Heather Lipford, and Audrey Rorrer. 2015. Flipped Classroom Strategies for CS Education. In Proceedings of the 46th ACM Technical Symposium on Computer Science Education (Kansas City, Missouri, USA) (SIGCSE '15). ACM, New York, NY, USA, 218-223. https://doi.org/10.1145/ 2676723.2677252

[6] Angela Siegel, Mark Zarb, and Teri Balser. 2021. Learning from COVID. In Proceedings of the 52nd ACM Technical Symposium on Computer Science Education (Virtual Event, USA) (SIGCSE '21). ACM, New York, NY, USA, 1356. https: //doi.org/10.1145/3408877.3439521

[7] Angela A. Siegel and Mark Zarb. 2016. Student Concerns Regarding Transition into Higher Education CS. In Proceedings of the 2016 ACM Conference on Innovation and Technology in Computer Science Education (Arequipa, Peru) (ITiCSE '16). ACM, New York, NY, USA, 23-28. https://doi.org/10.1145/2899415.2909581

[8] Angela A. Siegel, Mark Zarb, Richard Glassey, and Janet Hughes. 2019. Perspectives on the Student Transition into CS1. In Proceedings of the 2019 ACM Conference on Innovation and Technology in Computer Science Education (Aberdeen, Scotland Uk) (ITiCSE '19). ACM, New York, NY, USA, 168-169. https: //doi.org/10.1145/3304221.3325540

[9] Patriel Stapleton and Jeremiah Blanchard. 2021. Remote Proctoring: Expanding Reliability and Trust. In Proceedings of the 52nd ACM Technical Symposium on Computer Science Education (Virtual Event, USA) (SIGCSE '21). ACM, New York, NY, USA, 1243. https://doi.org/10.1145/3408877.3439671

[10] Richard Watermeyer, Tom Crick, Cathryn Knight, and Janet Goodall. 2021. COVID-19 and digital disruption in UK universities: afflictions and affordances of emergency online migration. Higher Education 81 (2021), 623-641. https: //doi.org/10.1007/s10734-020-00561-y

[11] Mark Zarb, Bedour Alshaigy, Dennis Bouvier, Richard Glassey, Janet Hughes, and Charles Riedesel. 2018. An International Investigation into Student Concerns Regarding Transition into Higher Education Computing. In Proceedings Companion of the 23rd Annual ACM Conference on Innovation and Technology in Computer Science Education (Larnaca, Cyprus) (ITiCSE 2018 Companion). ACM, New York, NY, USA, 107-129. https://doi.org/10.1145/3293881.3295780

[12] Mark Zarb, Angela Siegel, Ric Glassey, and Janet Hughes. 2021. Becoming a CS1 Student in the Time of COVID. In Proceedings of the 52nd ACM Technical Symposium on Computer Science Education (Virtual Event, USA) (SIGCSE '21). ACM, New York, NY, USA, 1362. https://doi.org/10.1145/3408877.3439518

[13] Mark Zarb and Angela A. Siegel. 2018. An Analysis of Pupil Concerns Regarding Transition into Higher Education. In Higher Education for All. From Challenges to Novel Technology-Enhanced Solutions, Alexandra Ioana Cristea, Ig Ibert Bittencourt, and Fernanda Lima (Eds.). Springer, 3-16. 